www.jmscr.igmpublication.org

Impact Factor 5.84

Index Copernicus Value: 83.27

ISSN (e)-2347-176x ISSN (p) 2455-0450

crossref DOI: _https://dx.doi.org/10.18535/jmscr/v5i7.227

Journal Of Medical Science And Clinical Research

IGM Publication

An Official Publication of IGM Publication

\title{
EEG Pattern in Alzheimer's Disease at Resting Condition
}

\author{
Authors \\ Sweta Soni ${ }^{1}$, Amitabh Dube ${ }^{2}$, Anoop Verma ${ }^{3}$, Kapil Gupta ${ }^{4}$, Jitendra Gupta \\ ${ }^{1}$ Ph.D. Scholar, ${ }^{2}$ Professor, ${ }^{4,5}$ Associate Professor \\ Department of Physiology, S.M.S. Medical College, Jaipur (Rajasthan), India \\ ${ }^{3}$ Senior Consultant, Santokba Durlabhji Institute of Neurosciences, Jaipur (Rajasthan), India. \\ Corresponding Author \\ Sweta Soni \\ Department of Physiology, S.M.S. Medical College, Jaipur (Rajasthan) India \\ Email: swetasoni925@gmail.com
}

\begin{abstract}
The aim of present Electroencephalography (EEG) study was to investigate the role of absolute power to discriminate Alzheimer's disease patient and normal elderly subjects. EEG was recorded at rest in age-sex matched 30 normal elderly subjects and 20 amnesic Alzheimer's disease patients (55-75 years) for Mini Mental State Examination. The EEG bands so evaluated were delta (0.2-3.9 Hz), theta $(4.0-7.9 \mathrm{~Hz})$, alpha (8.1- $12.9 \mathrm{~Hz})$, beta (13.0 -30.0 Hz) and gamma (30.1-80 Hz). A significant decrease MMSE score was observed in patients when compared to controls $(p=0.000)$. Amnesic Alzheimer's patients showed significant $(p=0.001)$ increased delta absolute power in fronto-central and parieto-occipital region of the brain. Theta bands tended to increased $(p=0.000)$ absolute power in parieto-occipital region in Amnesic Alzheimer's patients. Significant decreased $(p=0.000)$ alpha, beta and gamma absolute power were observed in both fronto-central and parieto-occipital region of the brain in Amnesic Alzheimer's patients. These results suggest that absolute power can discriminate Amnesic Alzheimer's patients from normal elderly subjects.

Keywords: Amnesic Alzheimer's patients, Electroencephalography (EEG), Mini Mental State Examination.
\end{abstract}

\section{INTRODUCTION}

The German Physician, Alois Alzheimer (in 1906) was the first to profile and define the clinical entity of Alzheimer's disease as a form of dementia way. Clinically diagnosed Alzheimer's disease, alone or in combination with other illness, accounts for up to $90 \%$ of reported dementia cases in the west [1]. Incidence rate of Alzheimer' disease was 9.19 (9.03-9.35) per 1000 personyears, reported from southern India ${ }^{[2]}$.The pathophysiology of Alzheimer's disease has been hypothesized and documented to be dysfunction of synaptic mechanisms with loss of functional neuronal pools. The features of Alzheimer disease are progressive deficits in memory and other aspects of cognition. Due to the deficits, patients with Alzheimer disease are unable to perform their daily course, leading to total dependence on their caregivers ${ }^{[3]}$. The DSM-IV-TR (American Psychiatric Association 2000) has laid down criteria for diagnosis of Alzheimer's disease which include impairment in memory, orientation, language, visual processing, executive function and praxis. 
The Mini Mental State Examination (MMSE) ${ }^{[4]}$ is used as a questionnaire - based tool that is employed to evaluate the cognitive profile of a subject/patient in clinical practice and helps in the determination of severity of dementia. Neuritic plaques and neurofibrillary tangles are the most important and characteristic pathognomic features in patients of Alzheimer's disease. Neuritic plaques are extracellular and microscopic, consisting of abnormal proteinaceous material known as amyloid beta that shows cross $\beta$ - sheet structure ${ }^{[3]}$. Oligomers of amyloid beta $(A \beta)$ cause synaptic loss by inducing metabolic and morphologic changes in pyramidal neurons of the hippocampus and neo-cortex that lead to cognitive decline in symptom complex of Alzheimer's disease ${ }^{[5]}$. Early onset of familial Alzheimer's disease prior to age 55 years, occurs in $<5 \%$ cases, who follow an inheritance pattern with mutations in the amyloid precursor protein gene (APP) on chromosome $21 \mathrm{q}^{[6]}$, in the presenilin 1 gene (PSEN 1) on chromosome 14q, and the presenilin 2 gene (PSEN 2, a homolog of PSEN 1) located on chromosome 1q ${ }^{[7]}$. These mutations cause excess production of $A \beta^{[8,9]}$. In Alzheimer's disease neurochemical abnormalities have been observed with respect to changing concentration of various neurotransmitters found in central nervous system. Acetylcholine is a neurotransmitter that has been implicated in cognitive neurophysiology and severity of the diseases has been observed to be correlated with the loss of cerebral cortical markers for acetylcholine metabolism ${ }^{[10]}$.

EEG provides insight about neuronal functioning and seemingly represents the functioning of the human mind in real-time by representing the summated and synthesised electrical signals originating from various regions of the brain. Electrical brain activity has been described following a wave pattern consisting of different types of frequency bands, namely delta $(0-4 \mathrm{~Hz})$, theta $(4-8 \mathrm{~Hz})$, alpha $(8-13 \mathrm{~Hz})$, beta $(13-30 \mathrm{~Hz})$ and gamma $(30-50 \mathrm{~Hz})$ waves ${ }^{[11]}$.In this context the present study was undertaken to explore neural dynamics as patterned through EEG rhythm and to appreciate an insight into the functioning of human mind in relation to cognitive decline.

\section{MATERIALS AND METHODS}

The study was conducted in the Department of Physiology in association with the Department of Neurology, S.M.S. Medical College, Jaipur and the Department of Neurosciences (Cognitive Function Section), Santokaba Durlabhji Memorial Hospital (SDMH), Jaipur. The study design was a hospital based observational case - control study. All experimental protocols had been approved by the Institutional Ethics Committee. Thirty healthy controls and twenty Amnesic Alzheimer's disease patients were enrolled in the present study. The Alzheimer's patients were recruited from the O.P.D. of Neurology, S.M.S. Medical College, Jaipur and the Department of Neurosciences (Cognitive Function Section), SDMH, Jaipur. All patients underwent history taking, physical and neurological examination, psychometric testing and neuroimaging procedures (magnetic resonance imaging, MRI with temporal lobe protocol of the brain) and laboratory testing to rule out other causes of cognitive impairment. The control group for study was composed of age and sex matched healthy subjects from the Institute.

The inclusion criteria adopted for the present study were: patients between 55 - 75 yrs., complaint by the patient, or report by a relative or the general practitioner of memory or other cognitive disturbances; patients rated and categorized with the standardized diagnostic and severity instrument of MMSE ${ }^{[4]}$. Patient with frontotemporal dementia, vascular dementia based on clinical and radiological grounds, extrapyramidal syndrome, psychiatric diseases, epilepsy, drug addiction, alcohol dependence, current or previous uncontrolled systemic diseases, traumatic brain injuries were excluded for the study.

\section{EEG recordings}

The EEG activity was recorded, continuously by using electrodes set in an elastic cap (Electro Cap International,) and positioned according to 
the 10-20 international system (Fp1, Fp2, Fz, F3, F4, F7, F8, Cz, C3, C4, T3, T4, T5, T6, Pz, P3, $\mathrm{P} 4, \mathrm{Oz}, \mathrm{O} 1, \mathrm{O} 2$ ). Impedance was kept below $5 \Omega$ and electrical activities, amplified with a bandpass filter of $0.5-30.0 \mathrm{~Hz}$, were digitized at sampling rate $256 \mathrm{~Hz}$. Recording of EEG was taken in a sound attenuated, dimly lit room. The patients were instructed to stay sit with closed eyes and relaxed and were awake during the procedure of basal and specialized manoeuvres EEG - test run. The EEG bands we use so evaluated were delta $(0.2-3.9 \mathrm{~Hz})$, theta (4.0-7.9 $\mathrm{Hz})$, alpha $(8.1-12.9 \mathrm{~Hz})$, beta $(13.0-30.0 \mathrm{~Hz})$ and gamma (30.1-80 Hz). QEEG was done for all the patients and controls using BESS (brain electro scan software) of the Axxonet System
(India). Artefact free epochs of 2 seconds each were chosen because after every of 2-3 seconds the changes both inclusive and exclusive in the amplitude were taking place more than $10 \%$ and their spectral content evaluated by means of Fast Fourier Transform analysis ${ }^{[12]}$.

\section{Statistical Analysis}

The Microsoft excel 2007 was used for statistically analysis of data. The unpaired t-test was used for the mean comparison of all parameters between patients with Alzheimer's disease and control subjects. With intention to avoid type 2 errors, we considered two - sided $\mathrm{p}$ values $<0.05$ to be significant.

\section{RESULTS AND DISCUSSION}

Table 1: Demographic and clinical data of the Alzheimer's disease and control population

\begin{tabular}{|l|l|c|c|c|}
\hline \multicolumn{2}{|l|}{$\begin{array}{l}\text { Demographic and } \\
\text { clinical Variables }\end{array}$} & $\begin{array}{l}\text { Patient } \\
(\mathrm{N}=20)\end{array}$ & $\begin{array}{c}\text { Control } \\
(\mathrm{N}=30)\end{array}$ & p value \\
\hline \multirow{3}{*}{ Gender } & Male & 11 & 21 & 0.281 \\
\cline { 2 - 4 } & Female & 9 & 9 & 0.281 \\
\hline \multirow{2}{*}{ Age } & Mean & 69.10 & 66.63 & \multirow{2}{*}{0.124} \\
\cline { 2 - 4 } & SD & 6.146 & 3.986 & \multirow{2}{*}{0.000} \\
\hline $\begin{array}{l}\text { MMSE } \\
\text { Score }\end{array}$ & Mean & 28.23 & 12.75 & 30.406 \\
\cline { 2 - 4 }
\end{tabular}

Table 2: Absolute Power of EEG band of delta, theta, alpha, beta and gamma during eye close session in fronto -central region of brain

\begin{tabular}{|l|c|c|c|}
\hline EEG band & Control & Patient & p value \\
\hline Delta & $20.40(7.33)$ & $24.07(9.16)$ & 0.001 \\
\hline Theta & $13.98(7.58)$ & $9.29(5.03)$ & 0.000 \\
\hline Alpha & $9.13(5.82)$ & $4.14(2.45)$ & 0.000 \\
\hline Beta & $11.34(7.19)$ & $5.58(3.24)$ & 0.000 \\
\hline Gamma & $8.53(4.43)$ & $3.75(3.36)$ & 0.000 \\
\hline
\end{tabular}

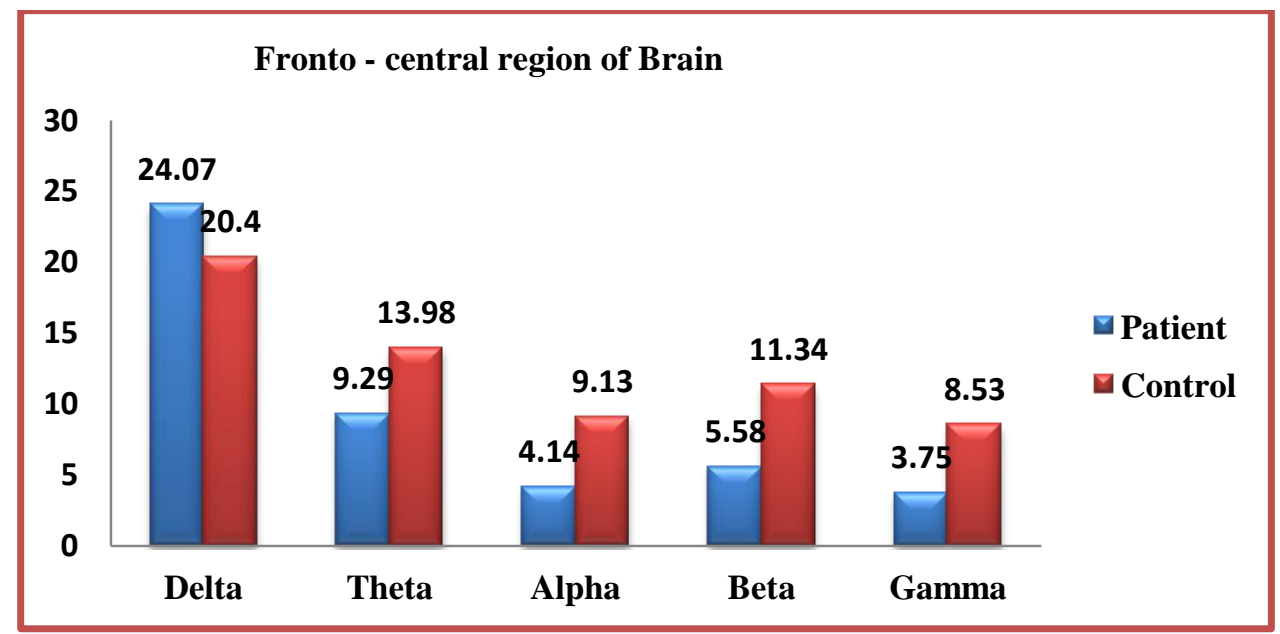

Graph 1: Absolute power of fronto - central region of brain during eye close session 
Table 3: Absolute Power of EEG band of delta, theta, alpha, beta and gamma during eye close session in parieto-occipital region of brain

\begin{tabular}{|l|c|c|c|}
\hline EEG band & Control & Patient & $\mathrm{p}$ value \\
\hline Delta & $21.12(8.36)$ & $25.45(8.27)$ & 0.001 \\
\hline Theta & $14.43(6.07)$ & $15.00(6.26)$ & 0.522 \\
\hline Alpha & $12.04(7.29)$ & $4.44(2.47)$ & 0.000 \\
\hline Beta & $12.37(8.35$ & $5.45(3.43)$ & 0.000 \\
\hline Gamma & $9.11(5.66)$ & $3.60(3.58)$ & 0.000 \\
\hline
\end{tabular}

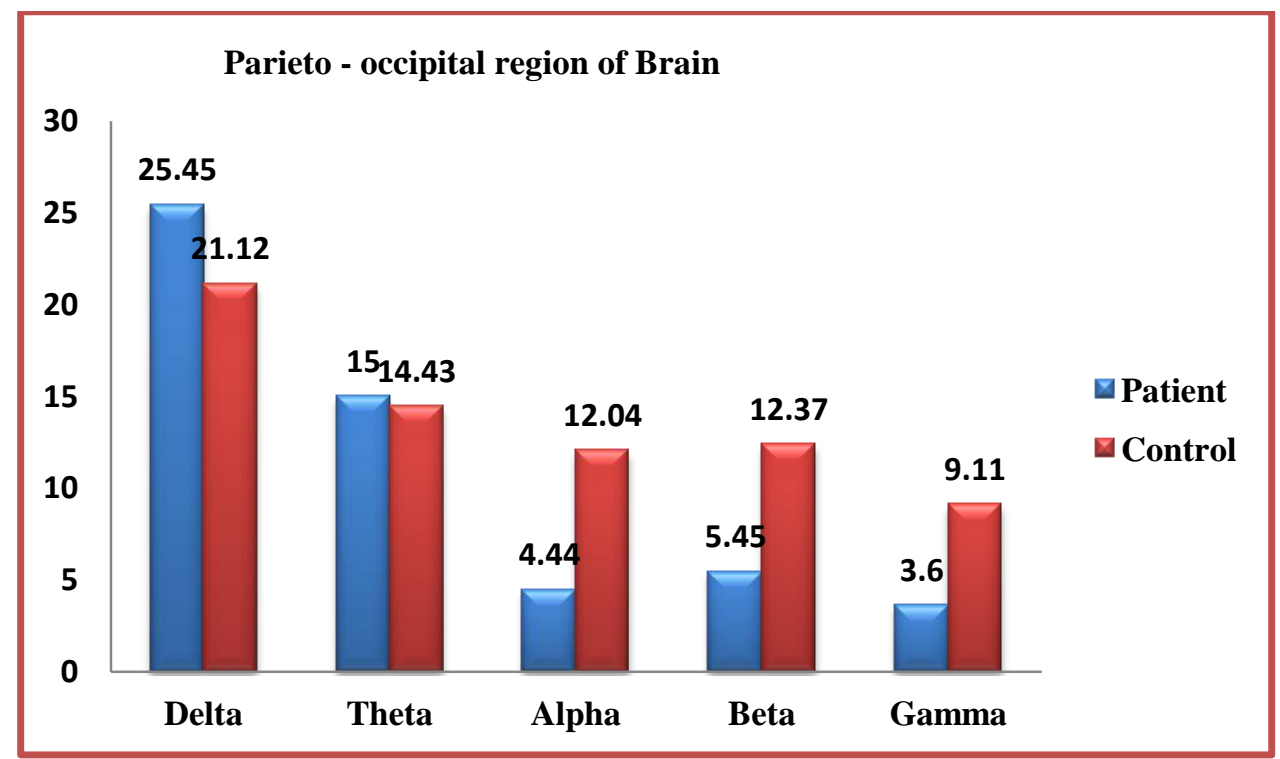

Graph 2: Absolute Power of parieto-occipital region during eye close session

In the present study an increased delta activity was observed during eye closed in fronto-central region (Table 2 and graph $1, \mathrm{p}=0.001$ ) and parieto-occipital region (Table 3 and graph 2, $\mathrm{p}=0.03$ ) in Alzheimer's disease (AD) patient. Theta band absolute power tended to increased in parieto-occipital region during eyes closed in patient group (Table 3 and graph 2, $\mathrm{p}=0.522$ ). Theta band absolute power decreased in frontocentral region (Table 2 and graph $1, \mathrm{p}=0.000$ ) Alpha, beta and gamma bands absolute power decreased in patient group in both fronto-central and parieto-occipital region (Table 2, 3 and graph $1,2, \mathrm{p}=0.000)$.

Moretti et al ${ }^{[13]}$ found higher delta power in AD patients. Deursen et al ${ }^{[14]}$ observed an increased power of low frequencies band (delta and theta) and decreased power of higher frequencies band (alpha and beta) in AD. Babiloni et al [15, 16] reported increased power of delta band and decreased power of alpha band in fronto-central region in Mild Cognitive Impairment (MCI) and
AD subjects. When compared to normal elderly subjects, patients with Alzheimer's disease have shown a power increase of topographically widespread delta and theta rhythms and a power decrease of posterior alpha $(8-13 \mathrm{~Hz})$ and beta $(13-30 \mathrm{~Hz})$ rhythms ${ }^{[17,18]}$. Patients with Alzheimer's disease are characterized by a power increase of parieto-occipital theta and delta rhythms as well as by a power reduction of alpha and beta rhythms in parieto-occipital regions ${ }^{[19]}$.

Compared to normal subjects, Alzheimer's disease (AD) patients are known to have 'slowing of the EEG,' namely through increase of the delta (0.5-4 $\mathrm{Hz}$ ) and theta (4-8 Hz) power, along with decrease of the alpha power $(8-13 \mathrm{~Hz})$. 'Slowing' of the EEG rhythms may be sensitive and correlate to dementia severity and disease progression from the earliest stages ${ }^{[20,21]}$. These findings are considered indirect evidence of the fundamental role of cholinergic system in modulating alpha rhythms, given the well-known selective deficit of acetylcholine occurring from 
the earliest stages of $\mathrm{AD}$. The alpha rhythm dominates the EEG power spectrum in resting normal subjects ${ }^{[22]}$. Scalp alpha rhythms result from sequences of inhibitory and excitatory postsynaptic potentials at the dendrites of cortical pyramidal neurons. These potentials depend mainly on the influence of near and distant cortical modules $^{[23]}$, as well as on the interactions of excitatory cortico-thalamo-cortical relay fibers and inhibitory thalamic reticular fibers ${ }^{[24]}$ An emerging feature of these integrated corticocortical and cortico-thalamo- cortical systems is that, in a resting condition, the higher the number of synchronously active neurons, the higher the amplitude of the alpha rhythm ${ }^{\text {[25]. }}$

In the present study we reported decrease MMSE score in patients when compared to controls $(p=0.000)$. Hsiao et $\mathrm{al}^{[26]}$ found that MMSE scores were strongly correlated with the magnitudes of spectral power at the theta and alpha bands in posterior portion of default brain network.

The limitation of the present study is a reduced amount of data. To define the diagnostic role of the absolute power in the diagnosis of dementia, in the future, the present study data need to be interpreted with caution and they need to be replicated before a firm conclusion can be deduced.

\section{CONCLUSION}

The present study concluded the role of delta absolute power to differentiate the Alzhemier's disease patient from the control group in frontocentral and parieto-occipital region. Compared to normal subjects the AD patients' EEGs were characterized by a significant reduction of the alpha, beta and gamma power. These results put into question the classical inverse relationship between the frequency and power in normal EEG rhythms and emphasize the differential role of specific abnormalities in Alzheimer's disease patients. Future investigations are needed to validate the clinical usefulness of these findings in early differential diagnosis, disease staging, and therapy monitoring.

\section{ACKNOWLEDGE}

We thank to Dr. Manisha Shankhla, Dr.Abhishek Saini, Dr. Kavita Yadav, Dr. Bhupendra Patel, Dr. Amit and Mrs. Shikha Saxena for their precious help in the development of the present study.

\section{REFERENCES}

1. Lim A, Tsuang D, Kukull W. Cliniconeuropathological correlation of Alzheimer's disease in a community-based case series. J Am Geriatr Soc 1999: 47: 564-569.

2. Mathuranath PS, George A, Ranjith N, Justus S, Kumar M.S, Menon R, Sarma PS, Verghese J. Incidence of Alzheimer's disease in India: a 10 years follow-up study. Neurol India Nov-Dec 60(6): 2012: 625-630. doi: 10.4103/0028-3886.105198.

3. Myron F, Lipton M. The American Psychiatric Publishing Textbook of Alzheimer Disease and Other Dementia. First Edition, 2009. Neural Comput. 1998 May 15: 10(4): 821-835.

4. Folstein MF, Folstein SE, McHugh PR. "Mini-mental state": a practical method of grading cognitive state of patients for the clinicians. J Psychiatr Res 1975: 12: 189198.

5. Sperling RA, Dickerson BC, Pihlajamaki M, Vannini P, LaViolette PS, Vitolo OV. Functional alterations in memory networks in early Alzheimer's disease. Neuromolecular Med. 2010: 12: 27-43. doi: 10.1007/s12017-009- 8109-7

6. Bertram L, Tanzi R.E. Thirty years of Alzheimer's disease genetics: the implications of systematic meta-analyses. Nat Rev Neurosci 2008: 9(10): 768-778. 10.1038/nrn2494.

7. Bertram L, Lill CM, Tanzi RE. The genetics of Alzheimer disease: back to the future. Neuron 2010: 68(2): 270-281. 10.1016/j.neuron.2010.10.013.

8. Murakami $\mathrm{K}$, Irie $\mathrm{K}$, Morimoto $\mathrm{A}$, Ohigashi H, Shindo M, Nagao M, Shimizu 
T, Shirasawa T. Neurotoxicity and physicochemical properties of Abeta mutant peptides from cerebral amyloid angiopathy: implication for the pathogenesis of cerebral amyloid angiopathy and Alzheimer's disease. J Biol Chem 2003: 278(46): 46179-46187. 10.1074/jbc.M301874200.

9. Tsubuki S, Takaki Y, Saido TC. Dutch, Flemish, Italian, and Arctic mutations of APP and resistance of Abeta to physiologically relevant proteolytic degradation. Lancet 2003 361(9373): 1957-1958. 10.1016/S01406736(03)13555-6

10. Bierer LM, Haroutunian V, Gabriel S. Neurochemical correlates of dementia severity in Alzheimer's disease: relative importance of the cholinergic deficits. J Neurochem 1995: 64: 749-760.

11. Estrada L, Soto C. Current Hypotheses and Research Milestones in Alzheimer's Disease. 2009: 7: 217-226.

12. Hughes JR, Jhon ER. Conventional and Quantitative Electroencephalography in Psychiatry. J Neuropsychiatry Clinical Neurosciences 1999: 11: 190-208.

13. Moretti DV, Babiloni C, Binetti G, Cassetta E, Fornod GD, Ferreric F, Ferrie R, Lanuzzae B, Miniussi C, Nobili F, Rodriguez G, Salinari S, Rossini PM. Individual analysis of EEG frequency and band power in mild Alzheimer's disease. Clinical Neurophysiology 2004: 115: 299308.

14. Deursen JA, Vuurman EF, Verhey FR, van Kranen-Mastenbroek VH, and Riedel WJ. Increased EEG gamma band activity in Alzheimer's disease and mild cognitive impairment. J Neural Transm 2009: 115(9): 1301-11.

15. Babiloni C, Frisoni G, Steriade $M$, Bresciani L, Binetti G, Del Percio C, Geroldi C, Miniussi C, Nobili F, Rodriguez G, Zappasodi F, Carfagna T,
Rossini PM. Frontal White Matter Volume and Delta EEG Sources Negatively Correlate In Awake Subjects With Mild Cognitive Impairment and Alzheimer's Disease. Clin Neurophysiol. 2006e: 117(5): 1113- 1129.

16. Babiloni C, Del Percio C, Bordet R, Bourriez JL, Bentivoglio M, Payoux P, Derambure P, Dix S, Infarinato F, Lizio R, Triggiani AI, Richardson JC, Rossini PM. Effects of acetylcholinesterase inhibitors and memantine on resting-state electroencephalographic rhythms in Alzheimer's disease patients. Clin. Neurophysiol. May 2013: 124(5): 837850. doi: 10.1016/j.clinph.2012.09.017. (Epub 2012 Oct 23).

17. Babiloni C, Binetti G, Cassetta E, Cerboneschi D, Dal Forno G, Del Percio C, Ferreri F, Ferri R, Lanuzza B, Miniussi C, Moretti DV, Nobili F, Pascual-Marqui RD, Rodriguez G, Romani GL, Salinari S, Tecchio F, Vitali P, Zanetti O, Zappasodi F, Rossini PM. Mapping distributed sources of cortical rhythms in mild Alzheimer's disease. A multicentric EEG study. Neuroimage 2004a: 22: 57-67.

18. Dierks T, Jelic V, Pascual-Marqui RD,Wahlund L, Julin P, Linden DE, Maurer K, Winblad B, Nordberg A. Spatial pattern of cerebral glucose metabolism (PET) correlates with localization of intracerebral EEGgenerators in Alzheimer's disease. Clin. Neurophysiol. 2000: 111: 1817-1824.

19. Coben LA, Danziger W, Storandt MA. longitudinal EEG study of mild senile dementia of Alzheimer type: changes at 1 year and at 2.5 years. Electroencephalogr. Clin. Neurophysiol 1985: 61: 101-112.

20. Ihl R, Dierks T, Martin EM, Frolich L, Maurer K. Topography of the maximun of the amplitude of EEG frequency in dementia of the Alzheimer type. Biol Psychiatry 1996: 39: 319-25. 
21. Nobili F, Copello F, Vitali P, Prastaro T, Carozzo S, Perego G, Rodriguez G. Timing of disease progression by quantitative EEG in Alzheimer's patients. J Clin Neurophysiol 1999: 16(6): 566-73.

22. Klimesch W. EEG alpha and theta oscillations reflect cognitive and memory performance: a review and analysis. Brain Res Rev 1999: 29: 169-95.

23. Nunez PL, Wingeier BM, Silberstein RB. Spatial-temporal structures of human alpha rhythms: theory, microcurrent sources, multiscale measurement and global binding of local networks. Hum Brain Mapp 2001:13:125-64.

24. Suffczynski P, Stilian K, Pfurtscheller G, Lopes da Silva FH. Compu- tational model of thalamo-cortical networks: dynamical control of alpha rhythms in relation to focal attention. Int J Psychophysiol 2001: 43: 25-40.

25. Pfurtscheller G, Lopes da Silva F. Eventrelated EEG/MEG synchroniza- tion and desynchronization: basic principles. Clin Neurophysiol 1999: 110:1842-57.

26. Hsiao FJ, Wang YJ, Yan SH, Chen WT, Lin YY. Altered oscillation and synchronization of default-mode network activity in mild Alzheimer's disease compared to mild cognitive impairment: an electrophysiological study. PLoS ONE 2013:8 (7): article e68792. 